\title{
Study on the Endogenous and Preventive Strategies of Financial Fraud in China's Listed Corporation under the New Normal
}

\author{
Hong $\mathrm{Ji}^{1, \mathrm{a}}$, Yunqin Zou ${ }^{2, \mathrm{~b}}$ \\ ${ }^{1}$ Jiangxi Normal University Science and Technology College, China \\ 2 Jiangxi Normal University Education College, China \\ ajxsdjh@vip.sina.com, ${ }^{\mathrm{b}} 707477684 @ q q . c o m$
}

Keywords: Listed company, Financial fraud, Endogenous, Prevention strategies.

\begin{abstract}
With the development of our social economy enters the new normal, and the development of China's capital market, the phenomenon of financial fraud and the consequences are increasingly serious, which not only hinder the healthy development of the listed Corporation, but also destroy the capital market resource allocation mechanism, and challenges the principle of fair, open and justice. Based on the interpretation of the main ways and channels of financial fraud in China, this paper reveals the endogenous of financial fraud in our country under the new norm, the corporate governance structure, information disclosure and audit independence, and then put forward the prevention strategies of financial fraud.
\end{abstract}

\section{Introduction}

In recent years, the huge financial fraud cases have occurred frequently, which has caused a huge credit crisis in China's securities market and endangered the credit basis, which makes the principle of fair and open justice be openly challenged, and then threaten the healthy development of the capital market. The serious consequences of financial fraud, the academic community and business increasingly recognized the necessity and urgency to guard against financial fraud of listed company, to purify the market environment and to promote the enterprise and the market's specifications, health, orderly development.

The type, ways and channels of financial fraud of listed companies in our country under the new normal state

The basic types of financial fraud of listed companies in our country. In Standards on Auditing for Certified Public Accountants, financial fraud is the audit unit of the management, government, employees or third parties to use deception to obtain improper or illegal interests through intentional behavior. The academic circles in our country defined financial fraud as the behavior that some personnel in order to obtain high profits and made deliberately false accounting information [1]. The listed Corporation's financial fraud includes three elements, namely, the subjective intent, with the fact of fraud and thereby causing loss to the objective of the fraud.

In the enterprise management, the weakness of internal control will produce financial fraud, from the point of view of accounting information, financial fraud can be divided into the principle of financial fraud, technical financial fraud, policy fraud and strategic fraud. The concealment and variability of financial fraud is strong, so it is not the same in the form of it, the basic types of it are: false statement and deceptive financial accounting report, the abuse of national accounting standards and accounting policies, adjust the business operations to implement earnings manipulation, fictitious business and so on. From the point of view of the level of fraud, corporate financial fraud can be divided into management fraud and employee fraud, the fundamental difference between these two types is that employee fraud is to obtain personal gain and damage to the interests of the enterprise, and the management of fraud is to harm the interests of enterprise external stakeholders. 
The main form of financial fraud of listed companies in our country. Listed corporation financial fraud through the accounting policy level generally before the semi annual report or the annual report will be announced, do everything possible to fictitious profits for cover up the major losses or create false results. common fraud ways of listed company under new normal includes false recognition of income and expenses, or affirm income ahead of schedule, deferred revenue, take non-operating income into revenues, or early confirmation fees, deferred expenses, charge excessive fees capitalization fraud; by manipulating the cash flow to whitewash fraud business performance; through the fictional facts such as fictitious sales and assets for fraud; Make use of the assets reorganization to profit.

The affiliated transaction channels of financial fraud of listed companies in our country. Listed Corporation financial fraud from the related transactions channel is mainly through the transfer of profits under the guise of related party transactions. Listed Corporation and related people to distort trade conditions, to adjust the profits by illegal or improper related trade, eventually to whitewash statements, usually design related transaction which has legal basis, no economic substance to fictitious business; purchase and sale with related enterprises at a high price or obviously unfair, use the price difference to shift profits; collect funds for related enterprises occupancy costs, using cheap or high-interest funds to adjust the financial costs; allocation of common costs or passed on management fees, advertising costs to the parent company; related transactions outside, loans from banks through their control of the listing corporation, to each other for the loan guarantees, related party transactions, performance related transaction channel construction made up of financial fraud.

\section{Endogenous of financial fraud of listed companies in China under the new normal}

Financial fraud is not a accident, it is a kind of social phenomenon. Accounting fraud of listed companies in China under the new norm is objective and fundamental, mainly reflects in:

Accounting system is missing. The system and policy of listed Corporation's accounting is the guarantee of the company's standard financial management, all economic operations of the corporation are carried out in the framework. However statutory accounting policy trend to provide greater accounting policy choice, but also left the door open for illegal molecular. On the one hand, accounting standards are flexible. The formulation of accounting standards is a political process, in the process, the interests of the parties concerned in the continuous battle against the balance; the final outcome is to take into account the interests of all parties, to give businesses a proper flexibility and accounting choice of space [2]. On the other hand, in the existing coverage in terms of specific accounting standard, though the general accounting standards part are comparatively perfect, but there are some specific business, such as: real estate, import, export, oil and natural gas, agriculture and other industries, and some special industries. They can only reference to general accounting standards in the specific operation. Yet general accounting standards is not for its special targeted rules, incomplete accounting principles for making false accounting information provides the operating space, the loose accounting policy also offers a wider range of options, this can make this kind of specific accounting manipulation exist a big space.

Corporate governance structure is not reasonable. On the one hand, the operator's rights are too large. With the development of the capital market, the equity is more and more dispersed and the flow speeds up, a large number of small and medium-sized shareholders may not care about the real financial situation of the enterprise and turn to speculative arbitrage. When the operator's power is too large, it is easy to make it lose its proper supervision, to a certain extent, contributed to the occurrence of financial fraud cases. On the other hand, the independent director can not remain truly independent and industrious. The current chairman and general manager of the listed Corporation accounted for $47.7 \%$, this structure is difficult to form a power balance. In addition, within the company's board of directors, board of supervisors and executive management has not really set up the decision-making power, the implementation of the supervision right and the right balance of powers of the mechanism. 
Although the external board of supervisors works hard, it is very difficult to carry out comprehensive and effective supervision in the management system of the internal and non - checks and balances.

Lack of audit independence. CPA system plays a very important role in established financial reporting credibility, to prevent the fraudulent financial information, but in fact, accounting firms is difficult to independent practice. On the one hand, some audit firms in order to retain customers, often biased in favor of the customer's request to audit, even if there is a problem, it is not directly pointed out in the audit report, so that the lack of independence of external audit institutions. On the other hand, the division responsibilities of internal audit are not clear. In addition to the board of supervisors of the Company Law stipulated, Functions related to the listed company internal audit institutions include the audit committee requirements by The Listed Corporate Governance Standards and internal already supervision agency, a total of three functional organization [3]. However, the division of responsibilities between the three departments is not reasonable, leading to the impact of the play, not to achieve the purpose of preventing the financial fraud of listed Corporation.

Information asymmetry. The information in the stock market is not the same as the main body of the securities market. Under the condition of information asymmetry, accounting fraud has the characteristics of concealment, and the information of the advantage of a party will use accounting fraud and make the inevitable result of adverse selection. Because of the separation of ownership and management in modern enterprises, the enterprise management and business owners, and investors have different information about the actual operation of the enterprise. Investors can not directly run the company, it is impossible to understand the situation better than the operator to the company, so they can only pay the agency costs, believe that operators will protect the interests of investors themselves. Those investors who are in the advantageous position in the management of the enterprise, or directly involved in the management of the actual production and management and in the control of the position, tend to know more about the production and operation of enterprises than the ordinary investors. That is, the marginal cost of obtaining financial information is much lower than that of the latter, therefore yield will be far higher than the latter.

Punishment is insufficient. On the one hand, the listed corporation's financial fraud lack of perfect and effective disciplinary mechanism. China's securities market regulation exists the phenomenon that "held high, falling gently", that is, the trustworthiness of the people can not get effective protection, dishonesty has not been severely sanctions, gave birth to the repeated financial fraud. On the other hand, the current status of law enforcement still exist the phenomenon that " non-observance and lax implementation of laws, and the allowance of law-breakers not being punished", to check out the fraud matters often to the economic punishment instead of administrative penalty and criminal punishment, try first, to make their mistake soundless serious, and then, to reduce it to nothing at all.

\section{Prevention strategies of financial fraud of listed corporation under the new normal}

Listed Corporation financial fraud has become a serious problem of social and economic problems, in order to effectively prevent, need to relevant parties make joint efforts.

Optimize the accounting system. On the one hand, the government should strengthen the construction of accounting system, and accelerate the reform of the accounting system. We must see that the existing accounting system exists defects and loopholes, constantly make effective and correct to the current accounting standards. On the other hand, the listed corporation should be based on their actual situation, improve the company's accounting system. Due to the flexibility of accounting policy change, accounting estimate change and accounting error change, the method of adjusting the initial or current profit or loss at will has a strong professional and private property. It is suggested that the accounting treatment of the listed corporation, especially the special industries, can be further revised to eliminate the flexibility of accounting treatment.

Improve the internal governance structure. On the one hand, we should improve the board of directors of the company. In the corporate governance framework, the board of directors is the core, 
especially the formation of the board of directors. To establish the balance mechanism of the board of directors, optimize the supervision function of the board, we can introduce a certain number of independent directors, play a special role of independent director, increase the proportion of non executive director, guarantee the rights and responsibilities of independent director, independent director system. On the other hand, we should optimize the ownership structure of the company. China's listed corporation is usually the absolute advantage of state-owned shares, while small and medium investor's equity dispersion, it is difficult to form the control of large shareholders. We should strengthen the motivation and ability for shareholders and other financial information to participate in monitoring, improve the company's property rights system. Only the property right system is perfect, can make the shareholder pursue the maximization of capital gain, can form its economic relationship with the company management, and then form the main body of the real financial report. In addition, we should to ensure the effective use of the board of supervisors. As far as possible let the shareholders meeting decide funds and compensation of the board of supervisors, to improve the individual quality of the members of the board of supervisors and professionalism, strengthen the sense of responsibility and professional level of the board of supervisors; in the actual operation to carry out the functions and powers of the board of supervisors shall clearly, and strengthen the transparency of the work of the commission, the use of legal and social supervision mechanism to prevent the generation of moral hazard.

Guarantee audit independence. On the one hand, to maintain the independence of Certified Public Accountants audit. The government should improve the CPA audit system. and enforce the accounting firm's rotation system, and through the practice of accounting firms, in order to achieve the purpose of enhancing the CPA audit independence, to prevent the listing Corporation and accounting firms to collusion, the emergence of common fraud, the creation of financial supervision committee, responsible for the registration, annual inspection, investigation and punishment, the establishment of certified public accountants. On the other hand, listed companies shall establish an audit committee, solely responsible for external audit employment, dismissal, supervision and matters relating to the remuneration; introduction of peer review system. Peer review system is a kind of industry self-regulation model of American Certified Public Accountants. The purpose is to review the audit quality control system, and to determine the extent to which it follows.

Improve the information disclosure system. Listed Corporation should continuously strengthen the breadth and depth of information disclosure, improve the timeliness, and constantly refine the relevant requirements of information disclosure, in order to reduce the possibility of using information disclosure system defects in financial fraud. On the one hand, the government should improve the internal control mechanism. The division of accounting and financial management division, to avoid the management of fraud; strengthen internal audit, internal audit of the accounting business, clear the position of the main financial information supply body, strengthen the internal supervision of financial information; supervision personnel in the enterprise to make their authority, property to maintain a high degree of independence. On the other hand, we should improve the legal system of listing Corporation financial accounting information disclosure. The standard system of financial accounting in our country is mainly composed of Company Law, Securities Act and Accounting Law, Enterprise Accounting Standards (including application guide, interpretation and other relevant provisions), Auditing Standards and Public Issuing Securities [4]. We should further improve the relevant accounting information disclosure laws and regulations; develop science, supporting the accounting regulation system; increase the listed company's financial information disclosure supervision, reform the multi management system, the establishment of listed company information ombudsman system; to develop a set of feasible listed companies financial information disclosure regulatory approach, the violations should be clearly defined, and resolutely put an end to irregularities.

Increase penalties for violations. On the one hand, the relevant regulatory authorities to increase the penalties for the relevant personnel, a substantial increase in the cost of financial fraud related personnel, so that the people will not only get the benefits from the fraud, but also to pay a price, thereby protecting the legitimate rights and interests of investors. On the other hand, we should 
improve the relevant provisions of the Criminal Law, strengthen the personal responsibility of the investigation. Proposed to amend the relevant articles of the Criminal Law, more responsible for the implementation of the accounting fraud unit and the persons who are directly responsible for the criminal and administrative penalties, change the past, impose a "fine" and strictly enforced to responsible and persons directly responsible individual "economic penalties and bear criminal responsibility, put an end to" fine "instead of" penalty "practice, make it in awe of the law did not dare to act rashly.

\section{Conclusions}

At present, listed corporation in our country is in the process of integration with the world, whether it is business philosophy or business practices are constantly developing and improving, the listed corporation's financial fraud problem is not solved overnight, it is a very complicated system. We must analyze its deep level problems and study its new techniques. We should treat it in a comprehensive way, from the listing Corporation accounting system, corporate governance structure, information disclosure, audit independence and so on.

\section{References}

[1] CharalambosT.SPahtis. Detecting False Financial Statements Using Published Data: Some Evidence from Greece, J. Managerial Auditing Jounral. (2002)Vol.17(4):179-191.

[2] Jing LIU, Jiahui YAN, The Root Of The Financial Fraud Of Listed Companies And Management Countermeasures, J. Friends of the accounting. 12(2015)116-117.

[3] Yang LIU, Accounting Fraud of Listed Company Problems and Governance, J. Times Finance, 4(2015)111-112.

[4] Yaoyao CHEN, The Listed Company Financial Fraud And Audit Countermeasure Analysis, J. Accounting Communication. 10(2015)87-89. 